Acta Crystallographica Section C

Crystal Structure

Communications

ISSN 0108-2701

\section{Supramolecular structures of four (Z)-5-arylmethylene-2-thioxothia- zolidin-4-ones: hydrogen-bonded dimers, chains of rings and sheets}

\author{
Paula Delgado, ${ }^{a}$ Jairo Quiroga, ${ }^{a}$ Justo Cobo, ${ }^{\text {b John }}$ \\ N. Low ${ }^{c}$ and Christopher Glidewell ${ }^{d}$.
}

a Grupo de Investigación de Compuestos Heterocíclicos, Departamento de Química, Universidad de Valle, AA 25360 Cali, Colombia, ${ }^{\mathbf{b}}$ Departamento de Química Inorgánica y Orgánica, Universidad de Jaén, 23071 Jaén, Spain, 'Department of Chemistry, University of Aberdeen, Meston Walk, Old Aberdeen AB24 3UE, Scotland, and ${ }^{\mathbf{d}}$ School of Chemistry, University of St Andrews, Fife KY16 9ST, Scotland

Correspondence e-mail: cg@st-andrews.ac.uk

Received 5 July 2005

Accepted 7 July 2005

Online 23 July 2005

In each of the four title compounds, namely ( $Z$ )-5-benzylidene-2-thioxothiazolidin-4-one, $\mathrm{C}_{10} \mathrm{H}_{7} \mathrm{NOS}_{2}$, (I), which crystallizes with $Z^{\prime}=2$ in space group $P 2_{1} / n$, (Z)-5-(4methylbenzylidene)-2-thioxothiazolidin-4-one, $\mathrm{C}_{11} \mathrm{H}_{9} \mathrm{NOS}_{2}$, (II), (Z)-2-thioxo-5-[4-(trifluoromethyl)benzylidene]thiazolidin-4-one, $\mathrm{C}_{11} \mathrm{H}_{6} \mathrm{~F}_{3} \mathrm{NOS}_{2}$, (III), and (Z)-5-(4-methoxybenzylidene)-2-thioxothiazolidin-4-one, $\mathrm{C}_{11} \mathrm{H}_{9} \mathrm{NO}_{2} \mathrm{~S}_{2}$, (IV), there is a very wide $\mathrm{C}-\mathrm{C}-\mathrm{C}$ angle $\left(\mathrm{ca} 130^{\circ}\right)$ at the methine $\mathrm{C}$ atom linking the two rings. Pairs of $\mathrm{N}-\mathrm{H} \cdots \mathrm{O}$ hydrogen bonds link the two independent molecules in (I) into a cyclic dimeric unit, and these units are further linked into complex sheets by three independent $\mathrm{C}-\mathrm{H} \cdots \pi$ (arene) hydrogen bonds. The molecules of (II) are linked by paired $\mathrm{N}-\mathrm{H} \cdots \mathrm{O}$ hydrogen bonds into centrosymmetric $R_{2}^{2}(8)$ dimers; the molecules of (III) and (IV) are linked into chains of rings, which are constructed from a combination of $\mathrm{N}-\mathrm{H} \cdots \mathrm{S}$ and $\mathrm{C}-\mathrm{H} \cdots \mathrm{O}$ hydrogen bonds in (III), and from a combination of $\mathrm{N}-\mathrm{H} \cdots \mathrm{O}$ and $\mathrm{C}-\mathrm{H} \cdots \mathrm{S}$ hydrogen bonds in (IV).

\section{Comment}

As part of a programme for the synthesis of new fused heterocyclic systems of potential biological application, we have been evaluating the use of $(Z)$-5-arylmethylene-2-thioxothiazolidin-4-ones as intermediates for cyclocondensation reactions, and we report here the structures of four such compounds, (I)-(IV), which have themselves been prepared by condensation of rhodanine (2-thioxothiazolidin4-one) with arylaldehydes using microwave irradiation in a solvent-free system.

The structure of (IV) has been reported previously (Okazaki et al., 1998) using diffraction data collected at ambient temperature; however, no discussion of the supramolecular structure was given and there are no atomic coordinates deposited in the Cambridge Structural Database (Allen, 2002; refcode GOVXIY). Compound (I) crystallizes in space group $P 2_{1} / n$ with $Z^{\prime}=2$, while compounds (II)-(IV) all crystallize with $Z^{\prime}=1$; a careful search for possible additional symmetry in (I) revealed none.

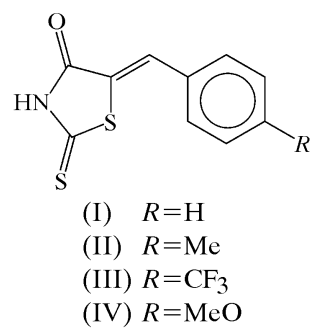

In each of (I)-(IV) (Figs. 1-4), the molecules are nearly planar, as shown by the values of the torsion angle (Table 1) defining the rotation of the aryl ring relative to the rest of the rigid skeleton. In addition, the methoxy $\mathrm{C}$ atom in (IV) is virtually coplanar with the adjacent aryl ring. In each compound, there is a fairly short intramolecular $\mathrm{C}-\mathrm{H} \cdots \mathrm{S}$ contact (Table 2), whose dimensions appear at first sight to

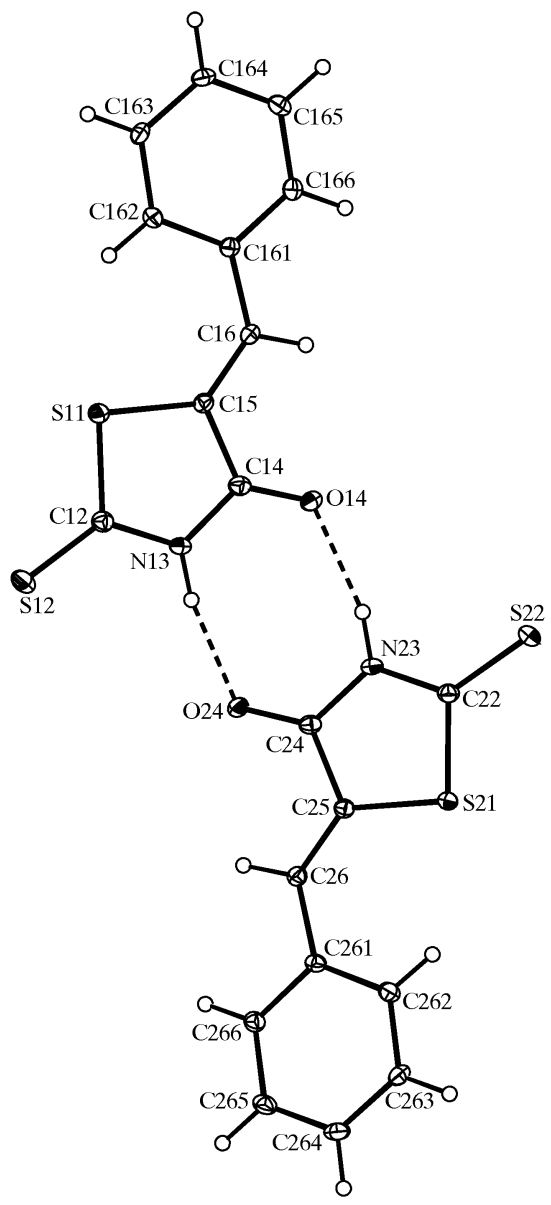

Figure 1

The two independent molecules of (I), showing the atom-labelling scheme and the $\mathrm{N}-\mathrm{H} \cdots \mathrm{O}$ hydrogen bonds (dashed lines). Displacement ellipsoids are drawn at the $30 \%$ probability level. 
suggest an attractive hydrogen-bonding interaction forming an S(6) ring (Bernstein et al., 1995). However, the bond angles associated with the central $\mathrm{C}-\mathrm{C}-\mathrm{C}$ fragment are all strongly indicative of a repulsive $\mathrm{C}-\mathrm{H} \cdots \mathrm{S}$ interaction; thus, the angles at the methine $\mathrm{C}$ atom linking the two rings are all around $130^{\circ}$. Moreover, the two exocyclic angles at thiazolidine atom C5 consistently differ by $c a 10^{\circ}$, and the exocyclic angles at benzene atom C61 consistently differ by $c a 6^{\circ}$, always in the sense that the larger angle is that contained within the $S(6)$ motif. All of these bond angles are thus consistent with a highly repulsive $\mathrm{C}-\mathrm{H} \cdots \mathrm{S}$ contact, and it is noteworthy that the repulsive contact is accommodated by distortion of the skeletal bond angles in preference to a rotation about the C6-C61 bond, which might at first sight appear to be the less energy-costly solution. In this respect, the behaviour of compounds (I)-(IV) resembles that of a series of 5-(arylmethylene)-1,3-dimethylpyrimidine-2,4,6(1H,3H,5H)-triones, whose essentially planar molecular skeletons are characterized by very wide $\mathrm{C}-\mathrm{C}-\mathrm{C}$ angles $\left(\mathrm{ca} 137-139^{\circ}\right)$ at the bridging methine $\mathrm{C}$ atom (Rezende et al., 2005).

In each of (I)-(IV), the ring angle at atom $\mathrm{S} 1$ is little greater than $90^{\circ}$, while in (IV), the exocyclic bond angles at the ring $\mathrm{C}$ atom ipso to the methoxy substituent show the usual deviations from $120^{\circ}$.

The supramolecular structure of (I) is considerably more complex than those of (II)-(IV), and it is the only one of the series (I)-(IV) in which $\mathrm{C}-\mathrm{H} \cdots \pi$ (arene) hydrogen bonds occur. For these reasons, we describe first (II), which has the simplest supramolecular structure, then (III) and (IV), and finally (I).

The molecules of (II) are linked by paired $\mathrm{N}-\mathrm{H} \cdots \mathrm{O}$ hydrogen bonds (Table 2 ) into a centrosymmetric $R_{2}^{2}(8)$ dimer (Fig. 5), but the only direction-specific interaction between these dimers is a dipolar carbonyl-carbonyl interaction

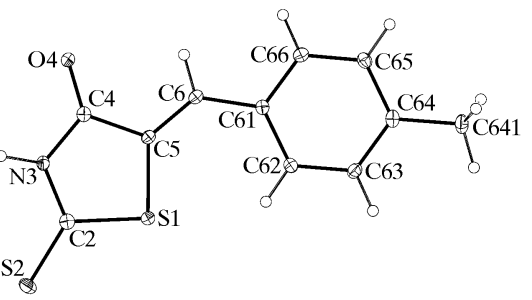

Figure 2

The molecule of (II), showing the atom-labelling scheme. Displacement ellipsoids are drawn at the $30 \%$ probability level.

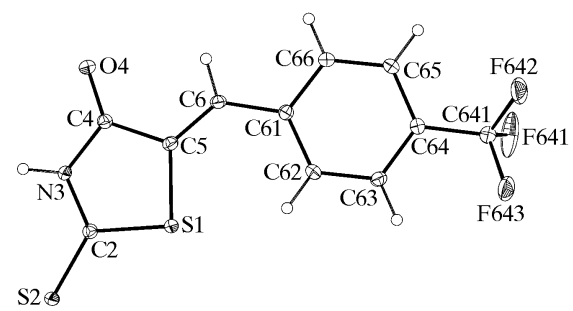

Figure 3

The molecule of (III), showing the atom-labelling scheme. Displacement ellipsoids are drawn at the $30 \%$ probability level. involving the $\mathrm{C} 4-\mathrm{O} 4$ bonds in the molecules at $(x, y, z)$ and $(1-x, 1-y, 1-z)$. The $\mathrm{O} 4 \cdots \mathrm{C} 4^{\mathrm{i}}$ distance is $3.042(2) \AA$ and the $\mathrm{C} 4-\mathrm{O} 4 \cdots \mathrm{C} 4^{\mathrm{i}}$ angle is $81.52(9)^{\circ}$ [symmetry code: (i) $1-x$, $1-y, 1-z]$, so that this interaction typifies the nearly rectangular antiparallel type II motif (Allen et al., 1998). The effect of this interaction is to link, albeit weakly, the hydrogenbonded dimers into a [100] chain. On the other hand, aromatic $\pi-\pi$ stacking interactions and intermolecular $\mathrm{C}-\mathrm{H} \cdots \mathrm{O}$ and $\mathrm{C}-\mathrm{H} \cdots \pi$ (arene) hydrogen bonds are all absent.

The notional replacement of the methyl group in (II) by a trifluoromethyl group in (III) causes a marked change in the supramolecular aggregation. The molecules of (III) are again linked into centrosymmetric $R_{2}^{2}(8)$ dimers, but now by means of paired $\mathrm{N}-\mathrm{H} \cdots \mathrm{S}$ hydrogen bonds, as opposed to the $\mathrm{N}-$ $\mathrm{H}$... O hydrogen bonds in (II). In addition, aryl atom C63 in the molecule at $(x, y, z)$ acts as a hydrogen-bond donor to ketone atom $\mathrm{O} 4$ in the molecule at $(-1+x,-1+y, z)$, so generating by translation a $C(8)$ chain running parallel to the [110] direction. The combination of the two hydrogen bonds then generates a chain of edge-fused rings along [110], in which $R_{2}^{2}(8)$ rings centred at $\left(n, n-\frac{1}{2}, \frac{1}{2}\right)$ ( $n=$ zero or integer)

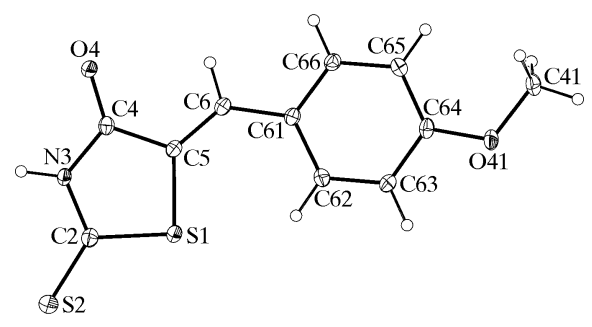

Figure 4

The molecule of (IV), showing the atom-labelling scheme. Displacement ellipsoids are drawn at the $30 \%$ probability level.

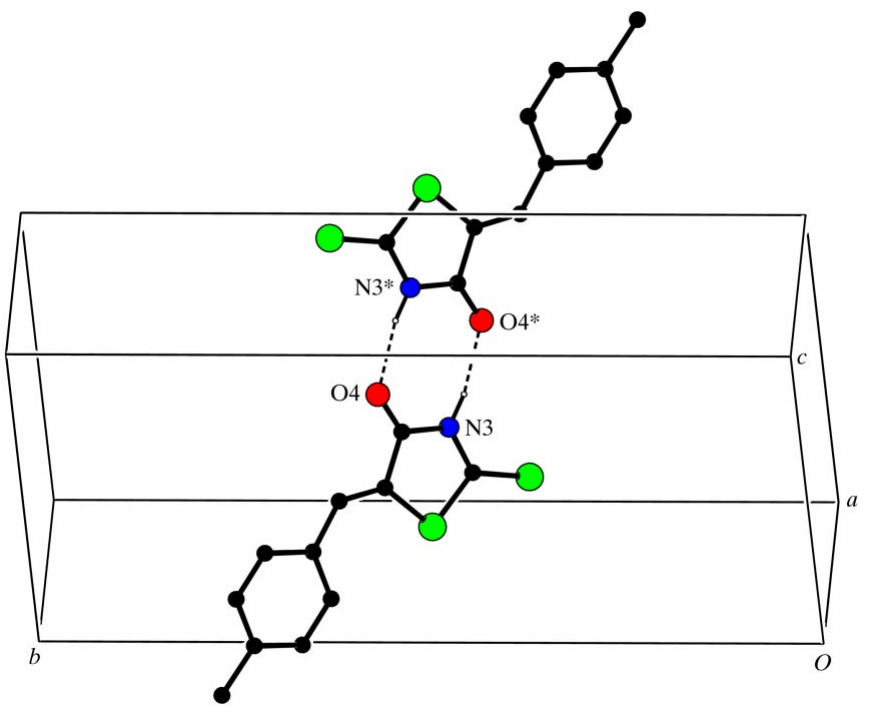

Figure 5

Part of the crystal structure of (II), showing the formation of a centrosymmetric hydrogen-bonded dimer. For clarity, $\mathrm{H}$ atoms bonded to $\mathrm{C}$ atoms have been omitted. Atoms marked with an asterisk $(*)$ are at the symmetry position $(2-x, 1-y, 1-z)$. 
alternate with $R_{4}^{4}(26)$ rings centred at $\left(n+\frac{1}{2}, n, \frac{1}{2}\right)(n=$ zero or integer) (Fig. 6). The trifluoromethyl groups lie on the outer edges of this chain; there are no direction-specific interactions between adjacent chains.

The supramolecular structure of (IV) also consists of a chain of rings, but now constructed from a combination of $\mathrm{N}-$ $\mathrm{H} \cdot \mathrm{OO}$ and $\mathrm{C}-\mathrm{H} \cdots \mathrm{S}$ hydrogen bonds as opposed to the combination of $\mathrm{N}-\mathrm{H} \cdots \mathrm{S}$ and $\mathrm{C}-\mathrm{H} \cdots \mathrm{O}$ hydrogen bonds in (III). Pairs of molecules are linked by $\mathrm{N}-\mathrm{H} \cdots \mathrm{O}$ hydrogen bonds into a centrosymmetric $R_{2}^{2}(8)$ dimer, just as in compound (II), and these dimers are linked by one component of a planar three-centre $\mathrm{C}-\mathrm{H} \cdots(\mathrm{S})_{2}$ interaction (Table 2). The shorter component in this system is probably a repulsive contact as discussed above, but the longer component appears to be attractive. Aryl atoms $\mathrm{C} 62$ in the molecules at $(x, y, z)$ and $(2-x, 1-y, 1-z)$, which form the $R_{2}^{2}(8)$ dimer centred at $\left(1, \frac{1}{2}, \frac{1}{2}\right)$, act as hydrogen-bond donors, respectively, to thione atoms $\mathrm{S} 2$ in the molecules at $(1-x,-y, 1-z)$ and $(1+x, 1+y$, $z$ ), which themselves form parts of the $R_{2}^{2}(8)$ dimers centred at $\left(0,-\frac{1}{2}, \frac{1}{2}\right)$ and $\left(2, \frac{3}{2}, \frac{1}{2}\right)$, respectively, so generating by inversion a complex chain of rings running parallel to the [110] direction and containing $S(6), R_{2}^{2}(8)$ and $R_{2}^{4}(8)$ rings (Fig. 7).

In (I), where the two independent molecules are related by an approximate, but not exact, twofold rotation, the molecules are again linked by a pair of $\mathrm{N}-\mathrm{H} \cdots \mathrm{O}$ hydrogen bonds (Table 2) into a dimeric aggregate (Fig. 1). These units are then linked into sheets by three independent $\mathrm{C}-$ $\mathrm{H} \cdots \pi$ (arene) hydrogen bonds, and the formation of this sheet is very readily analysed in terms of two one-dimensional

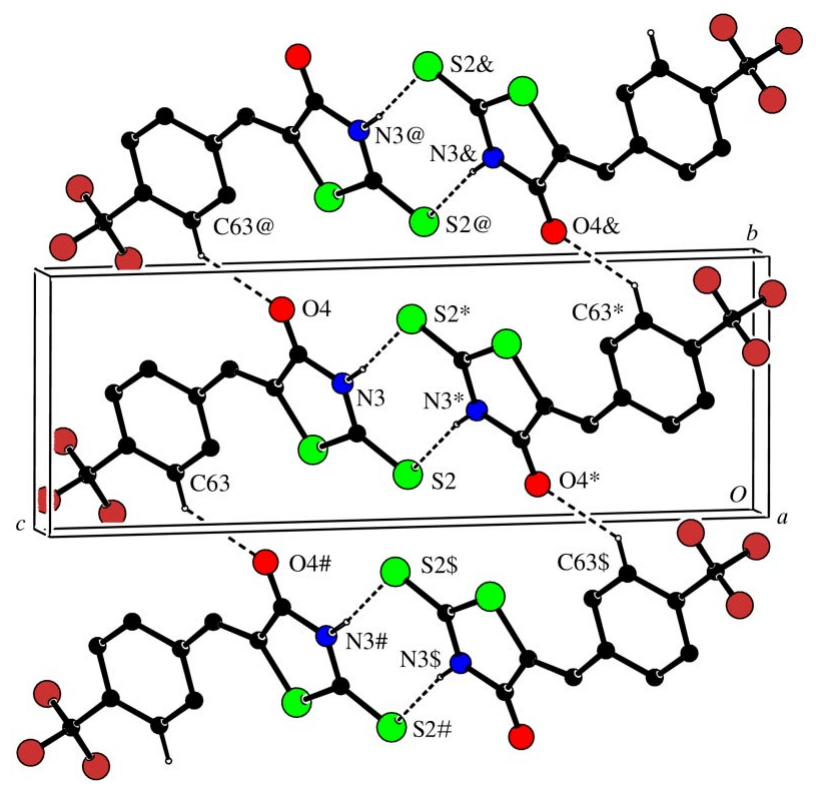

Figure 6

Part of the crystal structure of (III), showing the formation of a [110] chain of $R_{2}^{2}(8)$ and $R_{4}^{4}(26)$ rings. For clarity, $\mathrm{H}$ atoms not involved in the motifs shown have been omitted. Atoms marked with an asterisk $(*)$, a hash (\#), a dollar sign (\$), an ampersand (\&) or an 'at' sign (@) are at the symmetry positions $(2-x, 1-y, 1-z),(-1+x,-1+y, z),(1-x,-y$, $1-z),(3-x, 2-y, 1-z)$ and $(1+x, 1+y, z)$, respectively. substructures, one generated by inversion and the other generated by a $2_{1}$ screw axis.

In the first substructure, aryl atoms $\mathrm{C} 163$ and $\mathrm{C} 266$ at $(x, y$, $z$ ) act as hydrogen-bond donors, respectively, to aryl rings C261-C266 at $(1-x, 1-y, 1-z)$ and C161-C166 at $(1-x$, $-y, 1-z)$, so generating by inversion a chain along $\left(\frac{1}{2}, y, \frac{1}{2}\right)$

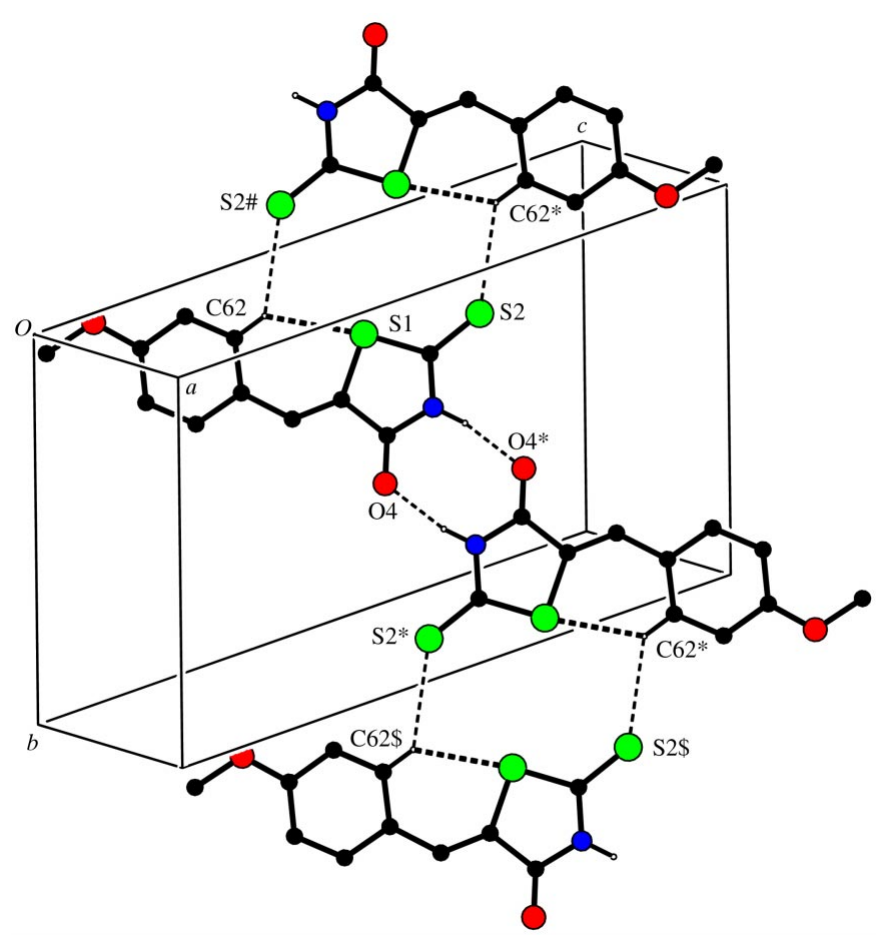

Figure 7

Part of the crystal structure of (IV), showing the formation of a [110] chain of rings generated by two-centre $\mathrm{N}-\mathrm{H} \cdots \mathrm{O}$ and three-centre $\mathrm{C}-$ $\mathrm{H} \cdots(\mathrm{S})_{2}$ interactions. For clarity, $\mathrm{H}$ atoms not involved in the motifs shown have been omitted. Atoms marked with an asterisk (*), a hash (\#) or a dollar sign $(\$)$ are at the symmetry positions $(2-x, 1-y, 1-z)$, $(1-x,-y, 1-z)$ and $(1+x, 1+y, z)$, respectively.
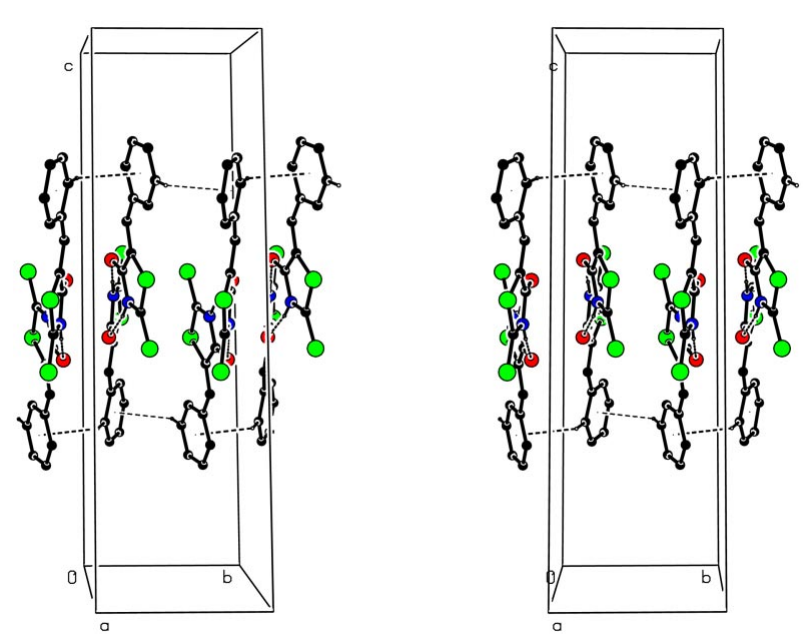

Figure 8

A stereoview of part of the crystal structure of (I), showing the formation of a hydrogen-bonded [010] chain generated by inversion. For clarity, $\mathrm{H}$ atoms not involved in the motifs shown have been omitted. 


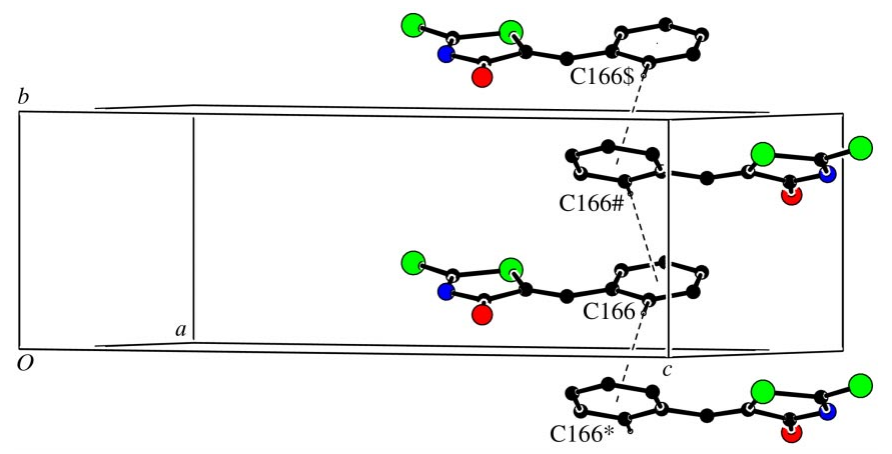

Figure 9

Part of the crystal structure of (I), showing the formation of a hydrogenbonded [010] chain generated by a screw axis. For clarity, $\mathrm{H}$ atoms not involved in the motifs shown have been omitted. Atoms marked with an asterisk $(*)$, a hash (\#) or a dollar sign (\$) are at the symmetry positions $\left(\frac{3}{2}-x,-\frac{1}{2}+y, \frac{3}{2}-z\right),(x,-1+y, z)$ and $\left(\frac{3}{2}-x, \frac{1}{2}+y, \frac{3}{2}-z\right)$, respectively.

containing three types of ring, two of which are centrosymmetric (Fig. 8). In the second substructure, which involves only one of the two independent molecules, aryl atom C166 at $(x, y, z)$ acts as a hydrogen-bond donor to the C161-C166 aryl ring at $\left(\frac{3}{2}-x,-\frac{1}{2}+y, \frac{3}{2}-z\right)$, so forming another [010] chain, this time generated by the $2_{1}$ screw axis along $\left(\frac{3}{4}, y, \frac{3}{4}\right)$ (Fig. 9). The molecule at $\left(\frac{3}{2}-x,-\frac{1}{2}+y, \frac{3}{2}-z\right)$ forms part of the inversion-generated chain lying along $(1, y, 1)$, and hence the combination of these two types of [010] chain generates a sheet parallel to $(10 \overline{1})$.

\section{Experimental}

Equimolar quantities (1 mmol of each component) of 2-thioxothiazolidin-4-one and the appropriate benzaldehyde $4-\mathrm{XC}_{6} \mathrm{H}_{4} \mathrm{CHO}$ [where $X=\mathrm{H}$ for (I), $\mathrm{CH}_{3}$ for (II), $\mathrm{CF}_{3}$ for (III) and $\mathrm{CH}_{3} \mathrm{O}$ for (IV)] were placed in open Pyrex-glass vessels in the absence of any solvent and irradiated in a domestic microwave oven for $3 \mathrm{~min}$ (at $600 \mathrm{~W}$ ); the reactions were monitored by thin-layer chromatography. The reaction mixtures were extracted with ethanol; after removal of this solvent, the products were recrystallized from dimethylformamide to give crystals suitable for single-crystal X-ray diffraction analysis. For (I) (orange crystals, m.p. $478 \mathrm{~K}$, yield 58\%), MS (70 eV) m/z (\%): 221 $\left(23, M^{+}\right), 134$ (100), 108 (40), 89 (8), 51 (4), 77 (2). For (II) (orange crystals, m.p. $504 \mathrm{~K}$, yield 56\%), MS $(70 \mathrm{eV}) \mathrm{m} / \mathrm{z}(\%): 235\left(39, \mathrm{M}^{+}\right)$, 148 (100), 115 (10), 91 (9), 77 (4), 59 (9). For (III) (orange crystals, m.p. $488 \mathrm{~K}$, yield 62\%), MS (70 eV) $\mathrm{m} / \mathrm{z}$ (\%): $291(10, M+2), 290$ (10, $M+1), 289\left(100, M^{+}\right), 152(35), 138(11)$. For (IV) (orange crystals, m.p. $516 \mathrm{~K}$, yield $87 \%)$, MS $(70 \mathrm{eV}) \mathrm{m} / \mathrm{z}(\%)$ : $164(9), 149(61)$, 121 (100), 89 (17), 77 (34), 63 (12).

\section{Compound (I)}

\section{Crystal data}

\section{$\mathrm{C}_{10} \mathrm{H}_{7} \mathrm{NOS}_{2}$}

$M_{r}=221.29$

Monoclinic, $P 2_{1} / n$

$a=11.7286(3) \AA$

$b=7.0215(2) \AA$

$c=23.7552(6) \AA$

$\beta=100.2630(12)^{\circ}$

$V=1925.00(9) \AA^{3}$

$Z=8$

\author{
$D_{x}=1.527 \mathrm{Mg} \mathrm{m}^{-3}$ \\ Mo $K \alpha$ radiation \\ Cell parameters from 4399 \\ reflections \\ $\theta=3.0-27.5^{\circ}$ \\ $\mu=0.51 \mathrm{~mm}^{-1}$ \\ $T=120(2) \mathrm{K}$ \\ Block, orange \\ $0.38 \times 0.20 \times 0.10 \mathrm{~mm}$
}

\section{Data collection}

Nonius KappaCCD diffractometer $\varphi$ and $\omega$ scans

Absorption correction: multi-scan (SADABS; Sheldrick, 2003)

$T_{\min }=0.888, T_{\max }=0.950$

20659 measured reflections

4399 independent reflections

\section{Refinement}

Refinement on $F^{2}$

$R\left[F^{2}>2 \sigma\left(F^{2}\right)\right]=0.038$

$w R\left(F^{2}\right)=0.095$

$S=1.03$

4399 reflections

253 parameters

$\mathrm{H}$-atom parameters constrained

\section{Compound (II)}

\section{Crystal data}

$\mathrm{C}_{11} \mathrm{H}_{9} \mathrm{NOS}_{2}$

$M_{r}=235.31$

Monoclinic, $P 2_{1} / c$

$a=4.9428$ (1)

$b=20.0473(8) \AA$

$c=10.7834$ (4) $\AA$

$\beta=90.753(2)^{\circ}$

$V=1068.43(6) \AA^{3}$

$Z=4$

\section{Data collection}

Nonius KappaCCD diffractometer $\varphi$ and $\omega$ scans

Absorption correction: multi-scan (SADABS; Sheldrick, 2003)

$T_{\min }=0.780, T_{\max }=0.964$

11502 measured reflections

2450 independent reflections

\section{Refinement}

Refinement on $F^{2}$

$R\left[F^{2}>2 \sigma\left(F^{2}\right)\right]=0.033$

$w R\left(F^{2}\right)=0.086$

$S=1.05$

2450 reflections

137 parameters

$\mathrm{H}$-atom parameters constrained

\section{Compound (III)}

Crystal data

\section{$\mathrm{C}_{11} \mathrm{H}_{6} \mathrm{~F}_{3} \mathrm{NOS}_{2}$}

$M_{r}=289.29$

Triclinic, $P \overline{1}$

$a=5.2859$ (2) $\AA$

$b=6.2263$ (3) $\AA$

$c=17.1885(8) \AA$

$\alpha=91.753(2)^{\circ}$

$\beta=95.326(3)^{\circ}$

$\gamma=90.129(3)^{\circ}$

$V=562.99(4) \AA^{3}$

\section{Data collection}

Nonius KappaCCD diffractometer $\varphi$ and $\omega$ scans

Absorption correction: multi-scan (SADABS; Sheldrick, 2003)

$T_{\min }=0.849, T_{\max }=0.957$

10662 measured reflections

2566 independent reflections
3154 reflections with $I>2 \sigma(I)$

$R_{\text {int }}=0.048$

$\theta_{\text {max }}=27.5^{\circ}$

$h=-15 \rightarrow 15$

$k=-8 \rightarrow 9$

$l=-30 \rightarrow 30$

\author{
$D_{x}=1.463 \mathrm{Mg} \mathrm{m}^{-3}$ \\ Mo $K \alpha$ radiation \\ Cell parameters from 2450 \\ reflections \\ $\theta=3.6-27.5^{\circ}$ \\ $\mu=0.47 \mathrm{~mm}^{-1}$ \\ $T=120(2) \mathrm{K}$ \\ Lath, orange \\ $0.56 \times 0.10 \times 0.08 \mathrm{~mm}$
}

2092 reflections with $I>2 \sigma(I)$

$R_{\text {int }}=0.041$

$\theta_{\text {max }}=27.5^{\circ}$

$h=-6 \rightarrow 6$

$k=-26 \rightarrow 26$

$l=-13 \rightarrow 14$

\section{$Z=2$}

$D_{x}=1.707 \mathrm{Mg} \mathrm{m}^{-3}$

Mo $K \alpha$ radiation

Cell parameters from 2566 reflections

$\theta=3.5-27.7^{\circ}$

$\mu=0.50 \mathrm{~mm}^{-1}$

$T=120(2) \mathrm{K}$

Lath, orange

$0.34 \times 0.18 \times 0.09 \mathrm{~mm}$

2144 reflections with $I>2 \sigma(I)$

$R_{\text {int }}=0.035$

$\theta_{\max }=27.7^{\circ}$

$h=-6 \rightarrow 6$

$k=-8 \rightarrow 8$

$l=-22 \rightarrow 22$ 
Table 1

Selected geometric parameters $\left(\AA,^{\circ}\right)$ for compounds (I)-(IV).

\begin{tabular}{|c|c|c|c|c|c|}
\hline Parameter & (I), mol 1 & (I), mol 2 & (II) & (III) & (IV) \\
\hline$x=$ & 1 & 2 & nil & nil & nil \\
\hline $\mathrm{S} x 1-\mathrm{C} x 2$ & $1.753(2)$ & $1.7502(19)$ & $1.7494(17)$ & $1.750(2)$ & $1.748(2)$ \\
\hline $\mathrm{C} x 2-\mathrm{N} x 3$ & $1.363(3)$ & $1.366(3)$ & $1.370(2)$ & $1.358(3)$ & $1.367(3)$ \\
\hline $\mathrm{N} x 3-\mathrm{C} x 4$ & $1.383(3)$ & $1.379(3)$ & $1.378(2)$ & $1.390(3)$ & $1.372(2)$ \\
\hline $\mathrm{C} x 4-\mathrm{C} x 5$ & $1.477(3)$ & $1.478(3)$ & $1.483(2)$ & $1.487(3)$ & $1.474(3)$ \\
\hline $\mathrm{C} x 5-\mathrm{S} x 1$ & $1.757(2)$ & $1.756(2)$ & $1.7553(16)$ & $1.753(2)$ & $1.758(2)$ \\
\hline $\mathrm{C} x 2-\mathrm{S} x 2$ & $1.635(2)$ & $1.626(2)$ & 1.6337 (17) & $1.643(2)$ & $1.624(2)$ \\
\hline $\mathrm{C} x 4-\mathrm{O} x 4$ & $1.225(2)$ & $1.224(2)$ & $1.2238(19)$ & $1.212(2)$ & $1.227(2)$ \\
\hline С $x 5-\mathrm{C} x 6$ & $1.351(3)$ & $1.348(3)$ & $1.344(2)$ & 1.347 (3) & $1.342(3)$ \\
\hline $\mathrm{C} x 6-\mathrm{C} x 61$ & $1.454(3)$ & $1.452(3)$ & $1.455(2)$ & $1.457(3)$ & $1.455(3)$ \\
\hline $\mathrm{C} x 5-\mathrm{S} x 1-\mathrm{C} x 2$ & $92.51(9)$ & $92.47(15)$ & $92.60(8)$ & $92.42(10)$ & $92.42(10)$ \\
\hline $\mathrm{S} x 1-\mathrm{C} x 5-\mathrm{C} x 6$ & $130.27(16)$ & $129.82(16)$ & $130.43(13)$ & $129.84(17)$ & $130.64(16)$ \\
\hline $\mathrm{C} x 4-\mathrm{C} x 5-\mathrm{C} x 6$ & $120.19(18)$ & $120.79(18)$ & $120.26(14)$ & 120.43 (18) & $120.14(18)$ \\
\hline $\mathrm{C} x 5-\mathrm{C} x 6-\mathrm{C} x 61$ & $130.97(19)$ & $130.13(19)$ & $130.98(15)$ & 130.25 (19) & 131.07 (19) \\
\hline $\mathrm{C} x 6-\mathrm{C} x 61-\mathrm{C} x 62$ & $124.02(18)$ & $124.71(15)$ & 123.97 (19) & $124.19(18)$ & \\
\hline $\mathrm{C} x 6-\mathrm{C} x 61-\mathrm{C} x 66$ & $117.51(18)$ & $118.04(18)$ & $117.50(14)$ & $118.14(19)$ & $118.22(18)$ \\
\hline $\mathrm{C} x 63-\mathrm{C} x 64-\mathrm{O} x 41$ & & & & & $115.42(18)$ \\
\hline $\mathrm{C} x 65-\mathrm{C} x 64-\mathrm{O} x 41$ & & & & & $124.70(19)$ \\
\hline $\mathrm{C} x 64-\mathrm{O} x 41-\mathrm{C} x 41$ & & & & & $117.45(16)$ \\
\hline $\mathrm{C} x 5-\mathrm{C} x 6-\mathrm{C} x 61-\mathrm{C} x 62$ & $2.9(3)$ & $4.5(3)$ & $-3.1(3)$ & $-3.6(4)$ & $-4.7(3)$ \\
\hline $\mathrm{C} x 63-\mathrm{C} x 64-\mathrm{O} x 41-\mathrm{C} x 41$ & & & & & $178.99(17)$ \\
\hline
\end{tabular}

\section{Refinement}

Refinement on $F^{2}$ $R\left[F^{2}>2 \sigma\left(F^{2}\right)\right]=0.038$

$w R\left(F^{2}\right)=0.103$

$S=1.07$

2566 reflections

163 parameters

$\mathrm{H}$-atom parameters constrained

\section{Compound (IV)}

\section{Crystal data}

$\mathrm{C}_{11} \mathrm{H}_{9} \mathrm{NO}_{2} \mathrm{~S}_{2}$

$M_{r}=251.31$

Monoclinic, $P 2_{1} / c$

$a=5.1314(2) \AA$

$b=10.4543$ (5) $\AA$

$c=20.5324(9) \AA$

$\beta=91.702(2)^{\circ}$

$V=1100.98(8) \AA^{3}$

$Z=4$

$D_{x}=1.516 \mathrm{Mg} \mathrm{m}^{-3}$

\section{Data collection}

Nonius KappaCCD diffractometer $\varphi$ and $\omega$ scans

Absorption correction: multi-scan

(SADABS; Sheldrick, 2003)

$T_{\min }=0.820, T_{\max }=0.963$

11472 measured reflections

2515 independent reflections

\section{Refinement}

Refinement on $F^{2}$

$R\left[F^{2}>2 \sigma\left(F^{2}\right)\right]=0.038$

$w R\left(F^{2}\right)=0.103$

$S=1.04$

2515 reflections

146 parameters

$\mathrm{H}$-atom parameters constrained

$$
\begin{gathered}
w=1 /\left[\sigma^{2}\left(F_{\mathrm{o}}^{2}\right)+(0.0459 P)^{2}\right. \\
\quad+0.5642 P] \\
\text { where } P=\left(F_{\mathrm{o}}^{2}+2 F_{\mathrm{c}}^{2}\right) / 3 \\
(\Delta / \sigma)_{\max }<0.001 \\
\Delta \rho_{\max }=0.50 \mathrm{e}^{-3} \\
\Delta \rho_{\min }=-0.54 \AA^{-3}
\end{gathered}
$$

Mo $K \alpha$ radiation

Cell parameters from 2515 reflections

$\theta=3.6-27.5^{\circ}$

$\mu=0.47 \mathrm{~mm}^{-1}$

$T=120(2) \mathrm{K}$

Plate, orange

$0.44 \times 0.18 \times 0.08 \mathrm{~mm}$

1958 reflections with $I>2 \sigma(I)$

$R_{\text {int }}=0.041$

$\theta_{\text {max }}=27.5^{\circ}$

$h=-6 \rightarrow 6$

$k=-13 \rightarrow 13$

$l=-26 \rightarrow 26$

\begin{tabular}{|c|c|c|c|c|c|}
\hline Compound & $D-\mathrm{H} \cdots A$ & $D-\mathrm{H}$ & $\mathrm{H} \cdots A$ & $D \cdots A$ & $D-\mathrm{H} \cdots A$ \\
\hline \multirow[t]{7}{*}{ (I) } & $\mathrm{N} 13-\mathrm{H} 13 \cdots \mathrm{O} 24$ & 0.95 & 1.94 & $2.829(2)$ & 168 \\
\hline & $\mathrm{N} 23-\mathrm{H} 23 \cdots \mathrm{O} 14$ & 0.95 & 1.99 & $2.868(2)$ & 165 \\
\hline & $\mathrm{C} 162-\mathrm{H} 162 \cdots \mathrm{S} 11$ & 0.95 & 2.56 & $3.281(2)$ & 133 \\
\hline & $\mathrm{C} 262-\mathrm{H} 262 \cdots \mathrm{S} 21$ & 0.95 & 2.50 & $3.231(2)$ & 134 \\
\hline & $\mathrm{C} 163-\mathrm{H} 163 \cdots C g 2^{\mathrm{i}}$ & 0.95 & 2.68 & $3.352(2)$ & 128 \\
\hline & $\mathrm{C} 166-\mathrm{H} 166 \cdots C g 1^{\mathrm{ii}}$ & 0.95 & 2.82 & 3.519 (2) & 131 \\
\hline & $\mathrm{C} 266-\mathrm{H} 266 \cdots C g 1^{\mathrm{iii}}$ & 0.95 & 2.76 & $3.435(2)$ & 129 \\
\hline \multirow[t]{2}{*}{ (II) } & $\mathrm{N} 3-\mathrm{H} 3 \cdots \mathrm{O} 4^{\mathrm{iv}}$ & 0.93 & 1.93 & 2.8507 (18) & 168 \\
\hline & $\mathrm{C} 62-\mathrm{H} 62 \cdots \mathrm{S} 1$ & 0.95 & 2.58 & $3.2911(16)$ & 132 \\
\hline \multirow[t]{3}{*}{ (III) } & $\mathrm{N} 3-\mathrm{H} 3 \cdots \mathrm{S} 2^{\mathrm{iv}}$ & 0.90 & 2.41 & $3.3048(18)$ & 172 \\
\hline & $\mathrm{C} 62-\mathrm{H} 62 \cdots \mathrm{S} 1$ & 0.95 & 2.51 & $3.230(2)$ & 133 \\
\hline & $\mathrm{C} 63-\mathrm{H} 63 \cdots \mathrm{O} 4^{\mathrm{v}}$ & 0.95 & 2.34 & $3.114(2)$ & 138 \\
\hline \multirow[t]{3}{*}{ (IV) } & $\mathrm{N} 3-\mathrm{H} 3 \cdots \mathrm{O} 4^{\mathrm{iv}}$ & 0.90 & 1.90 & $2.789(2)$ & 169 \\
\hline & $\mathrm{C} 62-\mathrm{H} 62 \cdots \mathrm{S} 1$ & 0.95 & 2.57 & $3.288(2)$ & 133 \\
\hline & $\mathrm{C} 62-\mathrm{H} 62 \cdots \mathrm{S} 2^{\mathrm{iii}}$ & 0.95 & 2.86 & $3.588(2)$ & 135 \\
\hline
\end{tabular}

Table 2

Hydrogen bonds and short intramolecular contacts $\left(\AA{ }^{\circ}\right)$ for compounds (I)-(IV)

$C g 1$ and $C g 2$ are the centroids of the C161-C166 and C261-C266 rings, respectively

Symmetry codes: (i) $1-x, 1-y, 1-z$; (ii) $\frac{3}{2}-x,-\frac{1}{2}+y, \frac{3}{2}-z$; (iii) $1-x,-y, 1-z$; (iv) $2-x, 1-y, 1-z$; (v) $-1+x,-1+y, z$.

For compound (I), the space group $P 2_{1} / n$ was uniquely assigned from the systematic absences. Likewise, the space group $P 2_{1} / c$ was uniquely assigned for both (II) and (IV). Although the unit cells for (II) and (IV) appear to have very different dimensions and shapes, with the $b$ parameter for (II) nearly double that for (IV), both cells have values of $\beta$ close to $90^{\circ}$, so that not only are their reduced cells similar in dimensions but both are close to orthorhombic metrics. Crystals of (III) are triclinic; the space group $P \overline{1}$ was selected and confirmed by the successful structure analysis. All $\mathrm{H}$ atoms were located from difference maps and then treated as riding atoms. $\mathrm{H}$ 


\section{organic compounds}

atoms bonded to $\mathrm{C}$ atoms were assigned $\mathrm{C}-\mathrm{H}$ distances of 0.95 (aromatic and methine) or $0.98 \AA$ (methyl) [with $U_{\text {iso }}(\mathrm{H})=1.2 U_{\text {eq }}(\mathrm{C})$, or $1.5 U_{\text {eq }}(\mathrm{C})$ for the methyl groups]. $\mathrm{H}$ atoms bonded to $\mathrm{N}$ atoms were allowed to ride at the $\mathrm{N}-\mathrm{H}$ distances $(0.90-0.93 \AA)$ deduced from the difference maps [with $U_{\text {iso }}(\mathrm{H})=1.2 U_{\text {eq }}(\mathrm{N})$ ]. In (III), the displacement parameters for the $\mathrm{F}$ atoms indicated some libration of the $\mathrm{CF}_{3}$ group, but it was not found necessary to model this group with more than three $\mathrm{F}$-atom sites.

For all compounds, data collection: COLLECT (Hooft, 1999); cell refinement: DENZO (Otwinowski \& Minor, 1997) and COLLECT; data reduction: $D E N Z O$ and COLLECT; program(s) used to solve structure: OSCAIL (McArdle, 2003) and SHELXS97 (Sheldrick, 1997); program(s) used to refine structure: OSCAIL and SHELXL97 (Sheldrick, 1997); molecular graphics: PLATON (Spek, 2003); software used to prepare material for publication: SHELXL97 and PRPKAPPA (Ferguson, 1999).

X-ray data were collected at the EPSRC X-ray Crystallographic Service, University of Southampton. JC thanks the Consejería de Innovación, Ciencia y Empresa (Junta de Andalucía, Spain) and the Universidad de Jaén for financial support. PD and JQ thank COLCIENCIAS and UNIVALLE (Universidad del Valle, Colombia) for financial support.
Supplementary data for this paper are available from the IUCr electronic archives (Reference: SK1860). Services for accessing these data are described at the back of the journal.

\section{References}

Allen, F. H. (2002). Acta Cryst. B58, 380-388.

Allen, F. H., Baalham, C. A., Lommerse, J. P. M. \& Raithby, P. R. (1998). Acta Cryst. B54, 320-329.

Bernstein, J., Davis, R. E., Shimoni, L. \& Chang, N.-L. (1995). Angew. Chem. Int. Ed. Engl. 34, 1555-1573.

Ferguson, G. (1999). PRPKAPPA. University of Guelph, Canada.

Hooft, R. W. W. (1999). COLLECT. Nonius BV, Delft, The Netherlands.

McArdle, P. (2003). OSCAIL for Windows. Version 10. Crystallography Centre, Chemistry Department, NUI Galway, Ireland.

Okazaki, M., Uchino, N., Ishihara, M. \& Fukunaga, H. (1998). Bull. Chem. Soc. Jpn, 71, 1713-1718.

Otwinowski, Z. \& Minor, W. (1997). Methods in Enzymology, Vol. 276, Macromolecular Crystallography, Part A, edited by C. W. Carter Jr \& R. M. Sweet, pp. 307-326. New York: Academic Press.

Rezende, M. C., Dominguez, M., Wardell, J. L., Skakle, J. M. S., Low, J. N. \& Glidewell, C. (2005). Acta Cryst. C61, o306-o311.

Sheldrick, G. M. (1997). SHELXS97 and SHELXL97. University of Göttingen, Germany.

Sheldrick, G. M. (2003). SADABS. Version 2.10. University of Göttingen, Germany.

Spek, A. L. (2003). J. Appl. Cryst. 36, 7-13. 